\title{
Sympathetic ophthalmia risk following vitrectomy: should we counsel patients?
}

Retinal surgery is being performed with increasing frequency as the advent of newer microsurgical techniques, perfluorocarbon liquids, and silicone oil tamponade has produced greater anatomical and functional success in preserving vision for both primary and repeat retinal surgery. ${ }^{1}$ With the ageing of the population, and associated increased incidence of retinal detachment and age related macular degeneration, pars plana vitrectomy, in particular, is being increasingly performed with expanding indications, such as for phakic retinal detachment repair, macular hole, submacular and retinal translocation surgery. ${ }^{12}$ Sympathetic ophthalmia is a rare disease, with an incidence of $0.03 / 100000,{ }^{3}$ causing bilateral severe posterior uveitis following penetrating trauma to one eye. Sympathetic ophthalmia has potentially devastating visual consequences if treatment is delayed or inadequate, and usually chronic immunosuppressive therapy is required in order to preserve good vision. ${ }^{4}$ Formerly, accidental penetrating eye trauma was the main cause but ocular surgery, particularly retinal surgery, has now become the main risk for sympathetic ophthalmia. ${ }^{34}$

The eye is regarded as an immune privileged site with the presence of blood-tissue barriers at the levels of the retinal vascular endothelium and the retinal pigment epithelium (RPE) and the purported lack of intraocular lymphatic drainage. ${ }^{5}$ Classically, the development of sympathetic ophthalmia requires scleral perforation, allowing previously sequestered ocular autoantigens to access conjunctival lymphatic drainage. ${ }^{6}$ Evidence for the precise autoantigen responsible in sympathetic ophthalmia is still inconclusive, as retinal antigens in the region of the rod outer segments, such as retinal S-antigen and interphotoreceptor retinoid binding protein, melanin associated antigens, and antigens derived from the RPE and choroid have all been implicated.

We compared data from a prospective study of all newly diagnosed sympathetic ophthalmia in the United Kingdom between July 1997 and October 1998 with hospital episode statistics from the Department of Health to ascertain retinal surgical risk factors for sympathetic ophthalmia. With informed patient consent, questionnaire data were obtained from UK-wide surveillance of ophthalmologists through the British Ophthalmological Surveillance Unit of the Royal College of Ophthalmologists. The nature of ocular surgical injury was determined in English patients developing sympathetic ophthalmia in the last 12 months of recruitment where the average response rate was $61 \%$. Finished consultant episodes (a period of patient care for one consultant) were counted for retinal surgical procedures for inpatients in NHS hospitals in England between April 1996 and March 1997 (latest figures available) (Table 1). Of nine sympathetic ophthalmia patients with retinal surgery as their causative ocular injury, seven were English. Of these seven patients, five had pars plana vitrectomy, corresponding to a sympathetic ophthalmia risk of one in 799 vitrectomies. A corresponding sympathetic ophthalmia risk of one in 1357 was determined for external retinal detachment repair, and for either pars plana vitrectomy or external retinal detachment repair, a risk of one in 1152 retinal surgical procedures was calculated.

Figures for new sympathetic ophthalmia cases are likely to be an underestimate owing to underreporting or errors in diagnosis but there may also be an underestimate of the number of retinal surgical procedures performed. Finished consultant episodes do not represent the number of patients undergoing certain operations, and as a patient may have more than one retinal operation within a year, we are unable to determine from these figures the sympathetic ophthalmia risk after a single or multiple retinal surgical procedures. While the data year for finished consultant episodes began 18 months before new sympathetic ophthalmia case data were collected, recent evidence has shown that the median time interval between initiating trauma and sympathetic ophthalmia onset is 12 months ${ }^{3}$ and the data years chosen are probably appropriate.

The most interesting finding of this study is that the current sympathetic ophthalmia risk of vitrectomy is nearly twice that of external retinal detachment repair, and is more than twice that of the previously reported $0.06 \%$ sympathetic ophthalmia risk after vitrectomy. ${ }^{8}$ Particularly immunogenic risks of pars plana vitrectomy are likely to be due to increased retinal manipulation and breakdown of the blood-retinal barrier, with release of previously sequestered retinal antigens, and possibly subclinical uveal incarceration at wound sites, a known immunogenic risk. ${ }^{9}$ Antigen presenting cells (APCs) in the form of dendritic cells have been found in the iris, ciliary body, and choroid, ${ }^{10} 11$ and operations which may produce uveal exposure, such as iridenclesis or pars plana vitrectomy with chronic access to uveoretinal antigens and APC stimulation, are implicated in sympathetic ophthalmia. Equally, it is not surprising that ocular surgery which causes significant disruption of uveoretinal tissue, such as neodimium:YAG cyclotherapy and again pars plana vitrectomy, are associated with sympathetic ophthalmia.

Table 1 Estimated sympathetic ophthalmia (SO) risk after retinal surgery

\begin{tabular}{llll}
\hline & $\begin{array}{l}\text { New SO cases } \\
\text { with previous } \\
\text { retinal surgery }\end{array}$ & $\begin{array}{l}\text { No of retinal } \\
\text { surgical } \\
\text { procedures } \\
\text { performed }\end{array}$ & $\begin{array}{l}\text { Estimated } S O \\
\text { risk }\end{array}$ \\
\hline $\begin{array}{l}\text { pergical procedure }{ }^{\star} \\
>1 \mathrm{PPV}\end{array}$ & 3 & & \\
Total & 2 & 3994 & 1 in 799 \\
$\begin{array}{l}1 \text { ext RD repair } \\
>1 \text { ext RD repair }\end{array}$ & 5 & & \\
Total & 1 & 4070 & 1 in 1357 \\
Total PPV or ext RD repair & 7 & 8064 & 1 in 1152
\end{tabular}

$\mathrm{PPV}=$ pars plana vitrectomy; ext $\mathrm{RD}$ repair $=$ external rhegmatogenous retinal detachment repair.

${ }^{\star}$ Data on retinal surgical risks for SO obtained with permission from Kilmartin et al. ${ }^{3}$

tData obtained from grossed hospital episode statistics from the Department of Health, London; Office for Population Census and Surveys 4 codes C54 (excluding retinal photocoagulation) and C79 (excluding anterior vitrectomy). 
The current sympathetic ophthalmia risk of vitrectomy is also more than twice the $0.05 \%$ risk of infectious endophthalmitis after vitrectomy. ${ }^{12}$ As patients are usually counselled about the risk of infection after surgery, and as sympathetic ophthalmia has potentially severe consequences, it may now be appropriate to counsel patients about the risk of sympathetic ophthalmia before performing vitrectomy.

Funding: The Wellcome Trust, Iris Fund for Prevention of Blindness.

DARA J KILMARTIN

ANDREW D DICK

JOHN V FORRESTER

Department of Ophthalmology, University of Aberdeen Medical School, Foresterhill, Aberdeen AB25 2ZD

Correspondence to: Dara J Kilmartin

opt046@abdn.ac.uk

1 Ah-Fat FG, Sharma MC, Majid MA, et al. Trends in vitreoretinal surgery at a tertiary referral centre: 1987-96. Br f Ophthalmol 1999;83:396-8.

2 Leaver PK. Trends in vitreoretinal surgery-time to stop and think. $B r \mathcal{F}$ Ophthalmol 1999;83:385-6.
3 Kilmartin DJ, Dick AD, Forrester JV. Prospective surveillance ofsympathetic ophthalmia in the United Kingdom and Republic of Ireland. Br 7 Ophthalmol 2000;84:259-63.

4 Chan C-C, Roberge FG, Whitcup SM, et al. Thirty-two cases of sympathetic ophthalmia: a retrospective study at the National Eye Institute, USA from 1982-1992. Arch Ophthalmol 1995;113:597-600.

5 Streilein JW, Willbanks GA, Cousins SW. Immunoregulatory mechanisms of the eye. F Neuroimmunol 1992;39:185-200.

6 Rao NA, Robin J, Hartman D, et al. The role of the penetrating wound in the development of sympathetic ophthalmia: experimental observations. Arch Ophthalmol 1983;101:102-4.

7 Kilmartin DJ. Pathogenesis and management of sympathetic ophthalmia: I. CME f Ophthalmol 1999;3:41-4.

8 Gass JDM. Sympathetic ophthalmia following vitrectomy. Am f Ophthalmol 1982;93:552-8.

9 Yamagami S, Tsuru T. Increase in orthotopic murine corneal transplantation rejection rate with anterior synechiae. Invest Ophthalmol Vis Sci 1999; 40:2422-6.

10 McMenamin PG, Crewe J, Morrison S, et al. Immunomorphological studies of macrophages and MHC class II-positive dendritic cells in the iris and ciliary body of the rat, mouse and human eye. Invest Ophthalmol Vis Sci 1994;35:3234-50.

11 Forrester JV, McMenamin PG, Holthouse I, et al. Localisation and characterisation of major histocompatibility complex clas II-positive cells in the posterior segment of the eye: implications for the induction of autoimmune uveoretinitis. Invest Ophthalmol Vis Sci 1994;35:64-77.

12 Kattan HM, Flynn HW, Plugfelder SC, et al. Nosocomial endophthalmitis survey. Ophthalmology 1991;98:227-38. 